Florida International University FIU Digital Commons

FIU Electronic Theses and Dissertations

University Graduate School

7-6-2016

\title{
Power Comparison of Some Goodness-of-fit Tests
}

Tianyi Liu

tliu019@fiu.edu

DOI: $10.25148 /$ etd.FIDC000750

Follow this and additional works at: https://digitalcommons.fiu.edu/etd

Part of the Statistical Methodology Commons

\section{Recommended Citation}

Liu, Tianyi, "Power Comparison of Some Goodness-of-fit Tests" (2016). FIU Electronic Theses and Dissertations. 2572. https://digitalcommons.fiu.edu/etd/2572

This work is brought to you for free and open access by the University Graduate School at FIU Digital Commons. It has been accepted for inclusion in FIU Electronic Theses and Dissertations by an authorized administrator of FIU Digital Commons. For more information, please contact dcc@fiu.edu. 


\section{FLORIDA INTERNATIONAL UNIVERSITY}

Miami, Florida

POWER COMPARISON OF SOME GOODNESS-OF-FIT TESTS

A thesis submitted in partial fulfillment of

the requirements for the degree of

MASTER OF SCIENCE

in

STATISTICS

by

Tianyi Liu

2016 
To: Dean Michael R. Heithaus

College of Arts, Sciences and Education

This thesis, written by Tianyi Liu, and entitled Power Comparison of Some

Goodness-of-fit Tests, having been approved in respect to style and intellectual content, is referred to you for judgment.

We have read this thesis and recommend that it be approved.

Gauri Ghai

Florence George

Zhenmin Chen, Major Professor

Date of Defense: July 6, 2016

The thesis of Tianyi Liu is approved.

Dean Michael R. Heithaus

College of Arts, Sciences and Education

Andrés G. Gil

Vice President for Research and Economic Development and Dean of the University Graduate School

Florida International University, 2016 


\title{
ABSTRACT OF THE THESIS \\ POWER COMPARISON OF SOME GOODNESS-OF-FIT TESTS
}

\author{
by \\ Tianyi Liu \\ Florida International University, 2016 \\ Miami, Florida \\ Zhenmin Chen, Major Professor
}

There are some existing commonly used goodness-of-fit tests, such as the Kolmogorov-Smirnov test, the Cramer-Von Mises test, and the Anderson-Darling test. In addition, a new goodness-of-fit test named $\mathrm{G}$ test was proposed by Chen and Ye (2009). The purpose of this thesis is to compare the performance of some goodness-offit tests by comparing their power.

A goodness-of-fit test is usually used when judging whether or not the underlying population distribution differs from a specific distribution. This research focus on testing whether the underlying population distribution is an exponential distribution.

To conduct statistical simulation, SAS/IML is used in this research. Some alternative distributions such as the triangle distribution, V-shaped triangle distribution are used. By applying Monte Carlo simulation, it can be concluded that the performance of the Kolmogorov-Smirnov test is better than the $\mathrm{G}$ test in many cases, while the $\mathrm{G}$ test performs well in some cases. 


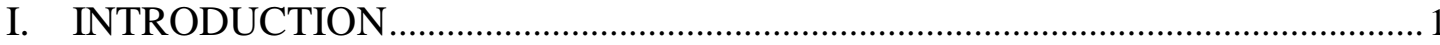

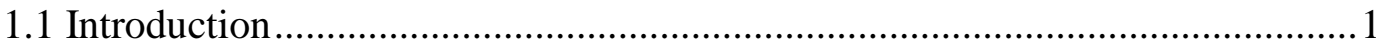

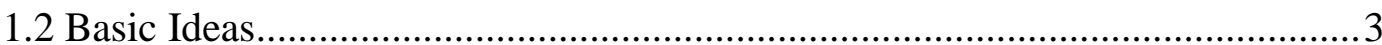

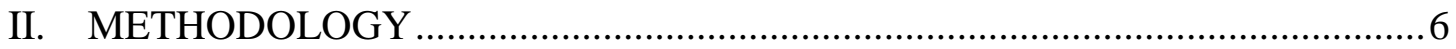

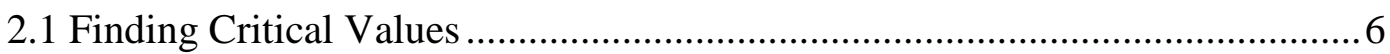

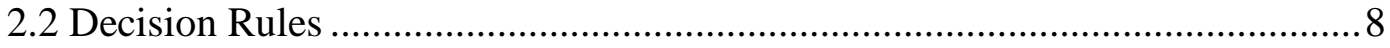

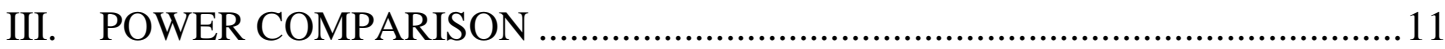

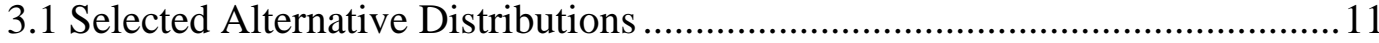

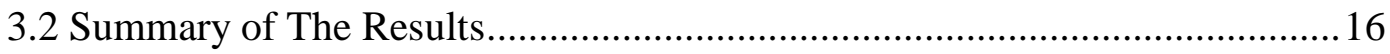

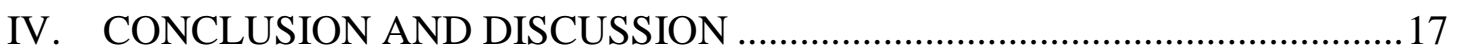

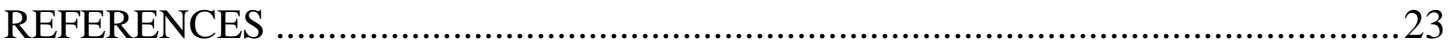




\section{LIST OF TABLES}

TABLES

PAGE

1. Critical Values of G Test Statistic..............................................18

2. Critical Values of K-S Test Statistic........................................ 19

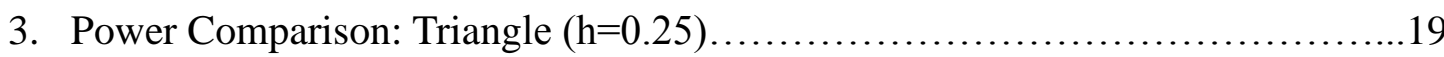

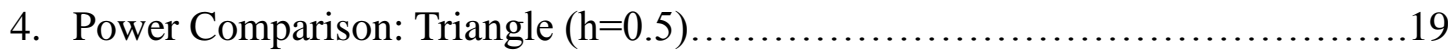

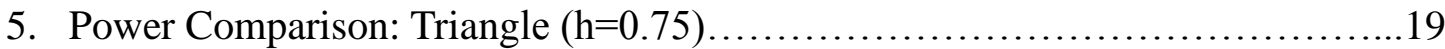

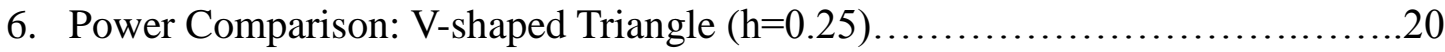

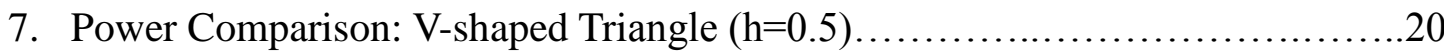

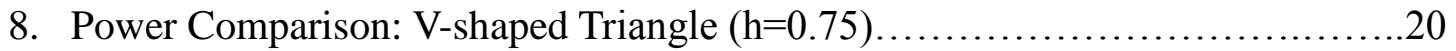




\section{LIST OF FIGURES}

FIGURES

PAGE

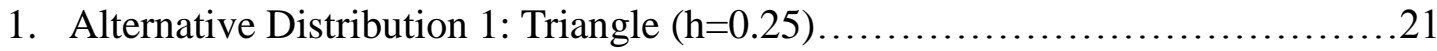

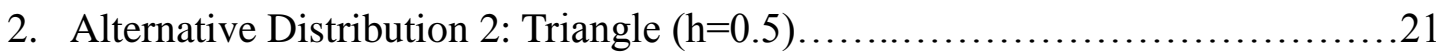

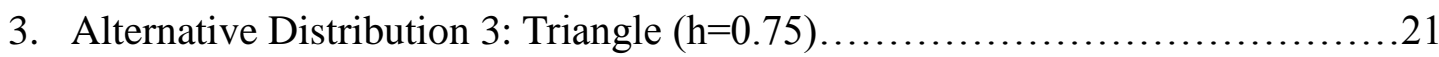

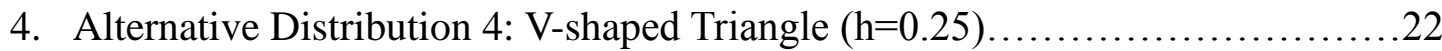

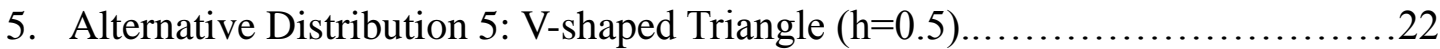

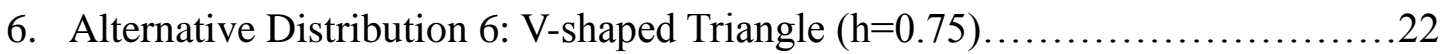




\section{CHAPTER I INTRODUCTION}

\subsection{Introduction}

The goodness-of-fit test is usually used when judging whether or not the underlying population distribution, from which a sample is drawn, differs from a specific distribution. The method can be used for testing any specified distributions. In the present thesis, the problem of testing whether a population distribution is an exponential distribution is discussed. Goodness-of-fit tests typically summarize the difference between observed values and expected values in the given model. Various test methods have been published in the literature. There are some commonly use goodness-of-fit tests including the Chi-squared test (Pearson, 1900), the KolmogorovSmirnov test (Kolmogorov, 1933 and Smirnov, 1939), the Cramer-Von Mises test (Cramer and von Mises, 1928), and the Anderson-Darling test (Anderson and Darling, 1952).

To determine which test should be applied while testing for different distributions, power comparison plays an important role. It has been shown that none of the existing statistical tests can be considered the "best" test. In the recent years, some new statistical tests have been developed to raise the power of goodness-of-fit test. Chen and Ye (2009) proposed a new method for testing whether the population distribution is a uniform distribution. The proposed test is originally for testing uniformity. However, by applying the well-known probability integral transformation, the proposed test can be used to test for any specified distribution. 
The current research will discuss the performance of some existing goodnessof-fit tests when they are used to check whether or not the underlying probability distribution is an exponential distribution. Monte Carlo simulation will be used to compare the power of those given tests.

The Chi-square test, also known as the Pearson's Chi-square test is a wellknown nonparametric goodness-of-fit test. Chi-square test is widely used in many cases due to the central limit theorem. However, when the sample size is small, the performance of Chi-square test is not satisfactory.

The Kolmogorov-Smirnov (K-S) test is the most popular nonparametric goodness-of-fit test. The test was proposed by Kolmogorov and Smirnov (1933 and 1939). The K-S test statistic D measures the distance between the empirical distribution function (EDF) using the observed data and the hypothesized distribution function $\mathrm{F}(\mathrm{x})$. The test statistic of the K-S test can be written as $D_{n}=\sup \left|F_{n}^{*}(x)-F(x)\right|$. Past research showed that K-S test may be preferred over the Chi-square test if the sample size is small.

The Cramer-von Mises test is an alternative of K-S test. The test was developed by Harald Cramer and Richard Edler von Mises (1928-1930). The test has been shown to be more powerful compared to the K-S test for some alternative hypotheses. The original test statistic, $\mathrm{W}^{2}$, is defined as $n \int_{-\infty}^{\infty}\left[F_{n}(x)-F^{*}(x)\right]^{2} d F^{*}(x)$, where $F_{n}$ is a given EDF of the observed data and $F^{*}$ is a CDF of the hypothesized distribution. 
Anderson and Darling (1952) further adapted the Cramer-von Mises test, and introduced a new test statistic $\mathrm{A}^{2}$, calculated by $n \int_{-\infty}^{\infty} \frac{\left[F_{n}(x)-F^{*}(x)\right]^{2}}{F^{*}(x)-\left(F^{*}(x)\right)^{2}} d F^{*}(x)$. It has been shown that the Anderson-Darling test can be more powerful than K-S test under some situations. For instance, when testing the normality of the observed data, Anderson-Darling test provides one of the most powerful statistic for detecting a normal distribution adequacy.

\subsection{Basic Ideas}

The test proposed by Chen and Ye uses a different method to test uniformity. A power study has shown that this test can provide quite decent power for testing uniformity. As mentioned above, the test can be used for testing any specified distribution after the probability integral transformation is used. In the present research, the exponential case is considered.

Let $\mathrm{X}_{1}, \mathrm{X}_{2}, \ldots, \mathrm{X}_{\mathrm{n}}$ be observations of a random sample from a population distribution with support set $[0,1]$. Suppose $X_{(1)}, X_{(2)}, \ldots, X_{(n)}$ are the corresponding order statistics. The hypotheses will be:

$\mathrm{H}_{0}$ : The population distribution is uniform distribution on $[0,1]$.

$\mathrm{H}_{1}$ : The population distribution is not uniform distribution on $[0,1]$.

The test statistic is defined as

$$
G\left(X_{1}, X_{2}, \ldots, X_{n}\right)=\frac{(n+1) \sum_{i=1}^{n+1}\left(X_{(i)}-X_{i f} \overline{1} \frac{1}{n+1}\right)^{2}}{n}
$$

Here $X_{(0)}=0$ and $X_{(n+1)}=1$. It can be shown that the value of $G\left(X_{1}, X_{2}, \ldots, X_{n}\right)$ is always 
between 0 and 1 . It can also be shown that $E\left(X_{(i)}-X_{(i-1)}\right)=\frac{1}{n+1}$ for $\mathrm{i}=1,2, \ldots, \mathrm{n}+1$. When $\mathrm{H}_{0}$ is true, the value of $\mathrm{G}\left(\mathrm{X}_{1}, \mathrm{X}_{2}, \ldots, \mathrm{X}_{\mathrm{n}}\right)$ should be small. On the other hand, if the value of $\mathrm{G}\left(\mathrm{X}_{1}, \mathrm{X}_{2}, \ldots, \mathrm{X}_{\mathrm{n}}\right)$ is too large, it could be an indication that $\mathrm{H}_{0}$ should be rejected. For any given $0<\alpha<1$, define $G_{\alpha}$ such that $P\left(G\left(X_{1}, X_{2}, \ldots, X_{n}\right)<G_{\alpha}\right)=\alpha$. Then $H_{0}$ will be rejected at $\alpha$ level of significance if $G\left(X_{1}, X_{2}, \ldots, X_{n}\right)>G_{1-\alpha}$.

To use this $G$ statistic to test whether the underlying distribution is an exponential distribution, the well-known probability integral transformation needs to be used.

Let $\mathrm{F}(\mathrm{x})$ be the CDF of exponential distribution, then

$$
F(x)=\left\{\begin{array}{l}
0, x \leq 0 \\
1-e^{-\lambda x}, x>0 .
\end{array}\right.
$$

Let $Y=F(X)=1-e^{-\lambda X}$. Then $\mathrm{Y}$ has a $\mathrm{U}[0,1]$ distribution on $[0,1]$. The $\mathrm{G}$ statistic is originally proposed for testing whether the data are from a uniform distribution. Using the above transformation, the $\mathrm{G}$ test can now be used to test whether the population distribution is an exponential distribution.

Here the test is valid only when the parameter $\lambda$ is known. However, the parameter $\lambda$ in the exponential distribution is usually unknown. The Lilliefor's method will be introduced to solve this problem. The basic idea is to estimate the parameter by calculating the sample mean. For the exponential distribution, $\hat{\lambda}=\frac{1}{\bar{x}}$.

Assume $\mathrm{X}$ is from an exponential distribution with parameter $\lambda$. Then the CDF will be:

$$
F(x)=+e^{-\lambda x}(x>0) .
$$


Let $Y=1-e^{-\lambda X}$. Then $\mathrm{Y}$ is uniformly distributed on $[0,1]$. This is because

$$
\begin{aligned}
F(y) & =P(Y \leq y) \\
& =P\left(1-e^{-\lambda X} \leq y\right) \\
& =P\left(e^{-\lambda X} \geq 1-y\right) \\
& =P\left(X \leq-\frac{\ln (1-y)}{\lambda}\right) \\
& =1-e^{-\lambda\left(-\frac{\ln (1-y)}{\lambda}\right)} \\
& =1-(1-y) \\
& =y \quad(0<y<1) .
\end{aligned}
$$

This is the CDF of the uniform distribution on $[0,1]$. The above proof shows that the parameter $\lambda$ has no contribution to $F(y)$. That means no matter what value of $\lambda$ is selected, the distribution after transformation is still a uniform distribution. The value of $\lambda$ can be arbitrarily selected at the beginning of the statistical simulation. The selection of the initial value of $\lambda$ will not change the distribution of the test statistic defined in (1). 


\section{CHAPTER II METHODOLOGY}

In the current research, the power of two goodness-of-fit tests, $G$ test and Kolmogorov-Smirnov test, will be compared when they are used to test whether the underlying distribution is an exponential distribution. The following are done in the present research: 1) Find the critical values of the two test statistics for different sample sizes; 2) Various alternative distributions are used to compare the power of these two tests. The power of the $\mathrm{G}$ test is compared to the power of KolmogorovSmirnov test in this study. The details related to power will be mentioned in Chapter III.

\subsection{Finding Critical Values}

\subsubsection{G Test}

The following are the steps for finding critical values:

(a) Generate a pseudo random sample $\mathrm{u}_{1}, \mathrm{u}_{2}, \ldots, \mathrm{u}_{\mathrm{n}}$ from the uniform distribution on $[0,1]$

(b) Choose a value of $\lambda$ arbitrarily, say $\lambda=1$. Calculate $x_{i}=-\frac{\ln \left(1-u_{i}\right)}{\lambda} \quad(i=1,2, \ldots, n)$;

(c) Compute the sample mean $\bar{x}$. Then the estimate of $\lambda$ is $\hat{\lambda}=\frac{1}{\bar{x}}$;

(d) Calculate $y_{i}=1-e^{-\hat{\lambda} x_{i}}(i=1,2, \ldots, n)$;

(e) Sort $\mathrm{y}_{1}, \mathrm{y}_{2}, \ldots, \mathrm{y}_{\mathrm{n}}$ to find the corresponding order statistic $\mathrm{y}_{(1)}, \mathrm{y}_{(2)}, \ldots, \mathrm{y}_{(\mathrm{n})}$, and define $\mathrm{y}_{(0)}=0, \mathrm{y}_{(\mathrm{n}+1)}=1$;

(f) Calculate $\mathrm{G}\left(\mathrm{y}_{1}, \mathrm{y}_{2}, \ldots, \mathrm{y}_{\mathrm{n}}\right)$ using equation (1);

(g) Repeat (a)-(f) k times ( $k=10,000,000)$; 
(h) Sort all the values of $\mathrm{G}$ and find the $90^{\text {th }}, 95^{\text {th }}, 99^{\text {th }}, 99.5^{\text {th }}$ and $99.9^{\text {th }}$ quantiles. For given $0<\alpha<1$, the critical values of the $G$ test are listed in Table 1 .

The decision rule will be to reject the null hypothesis at $\alpha$ level of significance if the test statistic is greater than $\mathrm{G}_{1-\alpha}$.

\subsubsection{Kolmogorov-Smirnov Test}

Let $\mathrm{X}_{1}, \mathrm{X}_{2}, \ldots, \mathrm{X}_{\mathrm{n}}$ be observations of a random sample from a population distribution with a distribution function $\mathrm{F}(\mathrm{x})$, and $\mathrm{F}_{\mathrm{n}}{ }^{*}(\mathrm{x})$ be the corresponding empirical distribution function. Then the Kolmogorov-Smirnov test statistic is:

$$
D_{n}=\sup _{x} F_{n}^{*}(-) F \quad(-) \mid \operatorname{m}_{n}^{+} \operatorname{Dx}^{-}(h
$$

where $D_{n}^{+}=\sup _{x}\left[F_{n}^{*}(x)-F(x)\right]$ and $D_{n}^{-}=\sup _{x}\left[F(x)-F_{n}^{*}(x)\right]$.

Let $\mathrm{X}_{(1)}, \mathrm{X}_{(2)}, \ldots, \mathrm{X}_{(\mathrm{n})}$ be the corresponding order statistic. Define $X_{(0)}=-\infty, X_{(n+1)}=\infty$.

Then $F_{n}^{*}(x)=\frac{i}{n}$ for $X_{(i)} \leq x \leq X_{(i+1)} \quad(\mathrm{i}=0,1, \ldots, \mathrm{n})$.

$$
\begin{aligned}
D_{n}^{+} & =\max _{0 \leq i \leq n} \sup _{X_{(i)} \leq x \leq X_{(i+1)}}\left\{\frac{i}{n}-F(x)\right\} \\
& =\max _{0 \leq i \leq n}\left\{\frac{i}{n}-\inf _{X_{(i)} \leq x \leq X_{(i+1)}} F(x)\right\} \\
& =\max _{0 \leq i \leq n}\left\{\frac{i}{n}-F\left(X_{(i)}\right)\right\} \\
& =\max \left\{\max _{1 \leq i \leq n}\left\{\frac{i}{n}-F\left(X_{(i)}\right)\right\}, 0\right\} .
\end{aligned}
$$

$$
D_{n}^{-}=\max \left\{\max _{1 \leq i \leq n}\left\{F\left(X_{(i)}\right)-\frac{i-1}{n}\right\}, 0\right\} .
$$

The procedure for finding critical values of the Kolmogorov-Smirnov test is as follows:

(a) Generate a pseudo random sample $\mathrm{u}_{1}, \mathrm{u}_{2}, \ldots, \mathrm{u}_{\mathrm{n}}$ from the uniform distribution on 
$[0,1]$

(b) Choose a value of $\lambda$ arbitrarily, say $\lambda=1$. Calculate $x_{i}=-\frac{\ln \left(1-u_{i}\right)}{\lambda} \quad(i=1,2, \ldots, n)$;

(c) Compute the sample mean $\bar{x}$. Then the estimate of $\lambda$ is $\hat{\lambda}=\frac{1}{\bar{x}}$;

(d) Calculate $y_{i}=\hat{\lambda} x_{i} \quad(\mathrm{i}=1,2, \ldots, \mathrm{n})$;

(e) Sort all the $\mathrm{y}_{1}, \mathrm{y}_{2}, \ldots, \mathrm{y}_{\mathrm{n}}$ to find the corresponding order statistic $\mathrm{y}_{(1)}, \mathrm{y}_{(2)}, \ldots, \mathrm{y}_{(\mathrm{n})}$;

(f) Calculate $D_{n}^{+}$and $D_{n}^{-}$using equations (3) and (4), and find out the bigger one of $D_{n}^{+}$and $D_{n}^{-}$which is the test statistic $D_{n}$;

(g) Repeat (a)-(f) k times $(\mathrm{k}=10,000,000)$;

(h) Sort all the values of $D_{n}$ and find the $95^{\text {th }}$ quantiles. For given $0<\alpha<1$, the critical values of the K-S test needed in power study are listed in Table 2. The decision rule will be to reject the null hypothesis at $\alpha$ level of significance if the test statistic is greater than $\mathrm{D}_{1-\alpha}$.

\subsection{Decision Rules}

The hypotheses are:

$\mathrm{H}_{0}$ : The population distribution is an exponential distribution.

$\mathrm{H}_{1}$ : The population distribution is not an exponential distribution.

\subsubsection{G Test}

The procedure for finding power of the $\mathrm{G}$ test statistic is as follows:

(a) Generate a pseudo random sample $\mathrm{u}_{1}, \mathrm{u}_{2}, \ldots, \mathrm{u}_{\mathrm{n}}$ from the uniform distribution on $[0,1]$ 
(b) For a particular alternative distribution, convert $\mathrm{u}_{1}, \mathrm{u}_{2}, \ldots, \mathrm{u}_{\mathrm{n}}$ to a sample $\mathrm{x}_{1}, \mathrm{x}_{2} \ldots, \mathrm{x}_{\mathrm{n}}$ from that alternative distribution (Details will be discussed in Chapter III);

(c) Compute the sample mean $\bar{x}$. Then the estimate of $\lambda$ is $\hat{\lambda}=\frac{1}{\bar{x}}$;

(d) Calculate $y_{i}=1-e^{-\hat{\lambda} x_{i}}(i=1,2, \ldots, n)$;

(e) Sort $\mathrm{y}_{1}, \mathrm{y}_{2}, \ldots, \mathrm{y}_{\mathrm{n}}$ to find the corresponding order statistic $\mathrm{y}_{(1)}, \mathrm{y}_{(2)}, \ldots, \mathrm{y}_{(\mathrm{n})}$, and define $\mathrm{y}_{(0)}=0, \mathrm{y}_{(\mathrm{n}+1)}=1$;

(f) Calculate $\mathrm{G}\left(\mathrm{y}_{1}, \mathrm{y}_{2}, \ldots, \mathrm{y}_{\mathrm{n}}\right)$ using equation (1). If $\mathrm{G}\left(\mathrm{y}_{1}, \mathrm{y}_{2}, \ldots, \mathrm{y}_{\mathrm{n}}\right)$ is greater than the corresponding critical value in Table 1 (here only $\alpha=0.05$ is used), reject $\mathrm{H}_{0}$. Then record rejection count;

(g) Repeat (a)-(f) k times $(\mathrm{k}=1,000,000)$. Iterate rejection count $\mathrm{k}$ times;

(h) Compute the power which is rejection count $/ \mathrm{k}$;

(i) Repeat procedure (a)-(h) for different sample sizes.

\subsubsection{Kolmogorov-Smirnov Test}

The followings are the steps for finding power of the Kolmogorov-Smirnov test statistic:

(a) Generate a pseudo random sample $\mathrm{u}_{1}, \mathrm{u}_{2}, \ldots, \mathrm{u}_{\mathrm{n}}$ from the uniform distribution on $[0,1]$

(b) For a particular alternative distribution, convert $\mathrm{u}_{1}, \mathrm{u}_{2}, \ldots, \mathrm{u}_{\mathrm{n}}$ to a sample $\mathrm{x}_{1}, \mathrm{x}_{2} \ldots, \mathrm{x}_{\mathrm{n}}$ from that alternative distribution (Details will be discussed in Chapter III);

(c) Compute the sample mean $\bar{x}$. Then the estimate of $\lambda$ is $\hat{\lambda}=\frac{1}{\bar{x}}$;

(d) Calculate $y_{i}=\hat{\lambda} x_{i} \quad(\mathrm{i}=1,2, \ldots, \mathrm{n})$;

(e) Sort $\mathrm{y}_{1}, \mathrm{y}_{2}, \ldots, \mathrm{y}_{\mathrm{n}}$ to find the corresponding order statistic $\mathrm{y}_{(1)}, \mathrm{y}_{(2)}, \ldots, \mathrm{y}_{(\mathrm{n})}$; 
(f) Calculate $D_{n}^{+}$and $D_{n}^{-}$using equation (3) and (4), and find out the bigger one which is the test statistic $D_{n}$. If $D_{n}$ is greater than the corresponding critical value in Table 2, reject $\mathrm{H}_{0}$. Then record rejection count;;

(g) Repeat (a)-(f) k times $(\mathrm{k}=1,000,000)$. Iterate rejection count $\mathrm{k}$ times;

(h) Compute the power which is rejection count $/ \mathrm{k}$;

(i) Repeat procedure (a)-(h) for different sample sizes.

Using the procedures above including the procedure in 2.2.1, the power of G test and K-S test for testing different alternative distributions with different sample sizes can be found. 


\section{CHAPTER III POWER COMPARISON}

The power of a hypothesis test is the probability of rejecting the null hypothesis correctly when the alternative hypothesis is true. A test with a high power (high rejection rate) is considered to be a good test method. The ideal power of a test is 1 , that is, always reject the null hypothesis when the null hypothesis is not true. In particular, the power of the test statistics discussed in this research is to reject the exponential hypothesis when population distribution is not exponential. When the power is closed to 1 , the test can be considered to be a good test.

In the present study, the power is estimated using the rate of rejection. The same test procedure will be repeated $\mathrm{k}$ times to test $\mathrm{k}$ sets of pseudo random samples from specified alternative distribution. The rejection rate among these $\mathrm{k}$ repetitions will be the power of this goodness-of-fit test. In this research, various alternative distributions such as triangle distribution, V-shaped triangle distribution will be used to conduct Monte Carlo simulation. The value of $\mathrm{k}$ is set to be $1,000,000$ to guarantee the accuracy of power comparison.

The sample size $\mathrm{n}$ is also an influential factor to the power. The power will increase when $n$ becomes large. In this study, $n=5,10,20,30,40,50$ will be used. Significance level $\alpha$ will be set as 0.05 .

\subsection{Selected Alternative Distributions}

\subsubsection{Triangle Alternative Distribution}

The probability density function of the triangle distribution is 


$$
f(x)=\left\{\begin{array}{l}
\frac{2 x}{h}, 0 \leq x \leq h \\
\frac{2(1-x)}{1-h}, h<x \leq 1 \\
0, \text { elsewhere; }
\end{array}\right.
$$

and the cumulative distribution function is:

$$
F(x)=\left\{\begin{array}{l}
0, x<0 \\
\frac{1}{h} x^{2}, 0 \leq x<h \\
1-\frac{(1-x)^{2}}{1-h}, h \leq x<1 \\
1, x \geq 1 .
\end{array}\right.
$$

Let $\mathrm{U}=\mathrm{F}(\mathrm{X})$. According to the probability integral transformation, $\mathrm{U}$ has a uniform distribution on $[0,1]$. This is because when $0 \leq \mathrm{X}<\mathrm{h}$,

$$
\begin{aligned}
F(u) & =P(U \leq u) \\
& =P\left(\frac{1}{h} X^{2} \leq u\right) \\
& =P\left(X^{2} \leq h u\right) \\
& =P(X \leq \sqrt{h u}) \\
& =\frac{1}{h} h u \\
& =u \quad(0 \leq u \leq h) ;
\end{aligned}
$$

and when $\mathrm{h} \leq \mathrm{X}<1$,

$$
\begin{aligned}
F(u) & =P(U \leq u) \\
& =P\left(1-\frac{(1-X)^{2}}{1-h} \leq u\right) \\
& =P\left((1-X)^{2} \geq(1-u)(1-h)\right. \\
& =P(1-X \geq \sqrt{(1-u)(1-h)}) \\
& =P(X \leq 1-\sqrt{(1-u)(1-h)}) \\
& =1-\frac{(1-1+\sqrt{(1-u)(1-h)})^{2}}{1-h} \\
& =1-(1-u) \\
& =u \quad(h<u \leq 1) .
\end{aligned}
$$


Above is the cdf of the uniform distribution on $[0,1]$.

In this study, a pseudo random sample from uniform distribution is generated first.

Then the inverse function of $\mathrm{U}$

$$
X_{i}=\left\{\begin{array}{l}
\sqrt{h U}, 0 \leq U \leq h \\
1-\sqrt{(1-U)(1-h)}, h<U \leq 1
\end{array}\right.
$$

has a triangle distribution with parameter $h(i=1,2, \ldots, n)$.SAS/iml can be used to perform the calculation after applying the transformation.

Here $h$ is a constant between 0 and 1 . The selected values are $h=0.25,0.5$, and 0.75 in this power study.

\section{Alternative distribution 1}

Select $\mathrm{h}=0.25$. This is a left-skewed triangle distribution. Figure 1 shows that the power is increasing along with the sample size becomes large. The K-S test performs better than $\mathrm{G}$ test in all cases. When sample size $\mathrm{n}$ is large enough $(\mathrm{n}=50)$, the power curve of these two tests merges together and the power is very close to 1 .

\section{Alternative distribution 2}

Select $\mathrm{h}=0.5$. This is a symmetric triangle distribution. Comparing to alternative distribution 1, the result is showed similarly in Figure 2. The power increases with $\mathrm{n}$ increases, and the K-S test still performs better than the $\mathrm{G}$ test. When the sample size increases to 20 , the power of $\mathrm{K}-\mathrm{S}$ test is approximate 1 . However, the power of $G$ test approaches to 1 when $n=40$. Two curves are merging faster than the previous case. 
Alternative distribution 3

Select $\mathrm{h}=0.75$. This is a right-skewed triangle distribution. It can be found in Figure 3, that the K-S test is more powerful than the $\mathrm{G}$ test when $\mathrm{n}<30$. After $\mathrm{n}$ reaches 30 , these two tests perform almost same.

\subsubsection{V-shaped Triangle Distribution}

The probability density function of the $\mathrm{V}$-shaped triangle distribution is:

$$
f(x)=\left\{\begin{array}{l}
2-\frac{2 x}{h}, 0 \leq x \leq h \\
2-\frac{2(1-x)}{1-h}, h<x \leq 1 \\
0, \text { elsewhere; }
\end{array}\right.
$$

and the cumulative distribution function is:

$$
F(x)=\left\{\begin{array}{l}
0, x<0 \\
2 x-\frac{1}{h} x^{2}, 0 \leq x<h \\
h+\frac{(x-h)^{2}}{1-h}, h \leq x<1 \\
1, x \geq 1 .
\end{array}\right.
$$

In 3.1.1 a transformation is used. Similarly, let $U=F(X)$. According to the probability integral transformation, $\mathrm{U}$ has a uniform distribution on $[0,1]$. This is because when $0 \leq \mathrm{X}<\mathrm{h}$,

$$
\begin{aligned}
F(u) & =P(U \leq u) \\
& =P\left(2 X-\frac{1}{h} x^{2} \leq u\right) \\
& =P\left(X^{2}-2 h X+h u \geq 0\right) \\
& =P\left(\left(X-\left(h-\sqrt{h^{2}-h u}\right)\right)\left(X-\left(h+\sqrt{h^{2}-h u}\right)\right) \geq 0\right)
\end{aligned}
$$

Since $0 \leq \mathrm{X}<\mathrm{h}$, then $X-\left(h+\sqrt{h^{2}-h u}\right)<0$, 


$$
\begin{aligned}
F(u) & =P\left(X-\left(h-\sqrt{h^{2}-h u}\right) \leq 0\right) \\
& =P\left(X \leq h-\sqrt{h^{2}-h u}\right) \\
& =2 h-2 \sqrt{h^{2}-h u}-2 h+u+2 \sqrt{h^{2}-h u} \\
& =u \quad(0 \leq u \leq h) .
\end{aligned}
$$

When $\mathrm{h} \leq \mathrm{X}<1$,

$$
\begin{aligned}
F(u) & =P(U \leq u) \\
& =P\left(h+\frac{(X-h)^{2}}{1-h} \leq u\right) \\
& =P\left(X^{2}-2 h X+h-u+h u \leq 0\right) \\
& =P((X-(h-\sqrt{(h-1)(h-u)}))(X-(h+\sqrt{(h-1)(h-u)})) \leq 0)
\end{aligned}
$$

Since $\mathrm{h} \leq \mathrm{X}<1$, then $X-(h-\sqrt{(h-1)(h-u)}>0$,

$$
\begin{aligned}
F(u) & =P(X-(h+\sqrt{(h-1)(h-u)})) \leq 0) \\
& =P(X \leq h+\sqrt{(h-1)(h-u)}) \\
& =h+\frac{(h-1)(h-u)}{1-h} \\
& =h-h+u=u \quad(h<u \leq 1) .
\end{aligned}
$$

Above is the cdf of the uniform distribution on $[0,1]$.

In this study, a pseudo random sample from uniform distribution is generated. Then

$$
X_{i}=\left\{\begin{array}{l}
h-\sqrt{h^{2}-h U}, 0 \leq U \leq h \\
h+\sqrt{(h-1)(h-U)}, h<U \leq 1
\end{array}\right.
$$

has a V-shaped triangle distribution $(\mathrm{i}=1,2, \ldots, \mathrm{n})$.

Here $\mathrm{h}$ is a constant between 0 and 1 . Select $\mathrm{h}=0.25,0.5$, and 0.75 in this power study.

\section{Alternative distribution 4}

Select $\mathrm{h}=0.25$. This is a left-skewed V-shaped triangle distribution. Figure 4 shows that the K-S test performs better than the $\mathrm{G}$ test when $\mathrm{n} \leq 30$. The powers of both tests are similar, and approach to 1 when sample size is greater than 30 . 


\section{Alternative distribution 5}

Select $\mathrm{h}=0.5$. This is a symmetric V-shaped triangle distribution. In Figure 5 , it can be easily found that the $\mathrm{G}$ test is better than the K-S test in all cases. As the sample size increases, the powers of both tests are increasing dramatically. The powers approach to 1 when $n=50$.

Alternative distribution 6

Select $\mathrm{h}=0.75$. This is a right-skewed $\mathrm{V}$-shaped triangle distribution. When $\mathrm{n}=5$, K-S test performs slightly better than $\mathrm{G}$ test. Figure 6 shows that the $\mathrm{G}$ test performs much better than K-S test when $n>10$. The power of $\mathrm{G}$ test increases faster than the K-S test does. However, compare to the previous 2 cases, the powers of both of the tests are low.

\subsection{Summary of the Results}

Based on the above power analysis, it can be found that:

(a) For all the triangle alternative distributions, including $\mathrm{h}=0.25,0.5,0.75$, the $\mathrm{K}-\mathrm{S}$ test performs better than the $\mathrm{G}$ test.

(b) For the left-skewed V-shaped triangle alternative distribution, the K-S test is better than the $\mathrm{G}$ test. However, for the symmetric and right-skewed V-shaped triangle alternative distribution, the $\mathrm{G}$ test performs better than the K-S test inversely, especially for the right-skewed case.

(c) For all the left-skewed alternative distributions, the K-S test performs better than the $\mathrm{G}$ test. 


\section{CHAPTER IV CONCLUSION AND DISCUSSION}

The goodness-of-fit test is widely used when checking whether the underlying population distribution differs from a specified distribution. In this research, exponential distribution is considered as a specific case. The concept of the goodnessof-fit test is to compute the difference between observed values and expected value in the given model. There are various commonly used goodness-of-fit tests such as the Chi-square test, the Kolmogorov-Smirnov test, the Cramer-Von Mises test, and the Anderson-Darling test. In addition, there is also an alternative $G$ test statistic was proposed by Chen and Ye (2009). It was proposed for testing uniformity originally. However, the probability integral transformation makes it possible to use this test to test for any distribution.

Power study is the core section of this research. The power of $G$ test and Kolmogorov-Smirnov test are compared by using the Monte Carlo simulation. Some alternative distributions such as triangle distribution and V-shaped triangle distribution are used to compare the power of these two tests. The result shows that KolmogorovSmirnov test performs better than $\mathrm{G}$ test when the alternative distribution has a triangle distribution. For the left-skewed V-shaped triangle alternative distribution, the K-S test is better than $\mathrm{G}$ test. However, for the symmetric and right-skewed V-shaped triangle alternative distribution, $\mathrm{G}$ test performs better than $\mathrm{K}-\mathrm{S}$ test. 
Table 1 Critical Values of G Test Statistic

\begin{tabular}{|c|c|c|c|c|c|c|}
\hline n & $\mathbf{G}_{0.900}$ & $\mathbf{G}_{0.950}$ & $\mathbf{G}_{0.975}$ & $\mathbf{G}_{0.990}$ & $\mathbf{G}_{0.995}$ & $\mathbf{G}_{0.999}$ \\
\hline 5 & 0.223 & 0.273 & 0.323 & 0.392 & 0.443 & 0.557 \\
\hline 6 & 0.193 & 0.234 & 0.277 & 0.334 & 0.379 & 0.481 \\
\hline 7 & 0.170 & 0.205 & 0.241 & 0.290 & 0.329 & 0.420 \\
\hline 8 & 0.151 & 0.182 & 0.213 & 0.256 & 0.290 & 0.371 \\
\hline 9 & 0.137 & 0.163 & 0.191 & 0.229 & 0.258 & 0.331 \\
\hline 10 & 0.124 & 0.148 & 0.172 & 0.206 & 0.233 & 0.298 \\
\hline 11 & 0.114 & 0.135 & 0.157 & 0.187 & 0.211 & 0.269 \\
\hline 12 & 0.105 & 0.124 & 0.144 & 0.171 & 0.193 & 0.246 \\
\hline 13 & 0.097 & 0.115 & 0.133 & 0.157 & 0.177 & 0.225 \\
\hline 14 & 0.091 & 0.106 & 0.123 & 0.145 & 0.164 & 0.208 \\
\hline 15 & 0.085 & 0.099 & 0.114 & 0.135 & 0.151 & 0.192 \\
\hline 16 & 0.080 & 0.093 & 0.107 & 0.126 & 0.141 & 0.179 \\
\hline 17 & 0.075 & 0.088 & 0.100 & 0.118 & 0.132 & 0.167 \\
\hline 18 & 0.071 & 0.083 & 0.094 & 0.111 & 0.124 & 0.156 \\
\hline 19 & 0.067 & 0.078 & 0.089 & 0.104 & 0.116 & 0.146 \\
\hline 20 & 0.064 & 0.074 & 0.084 & 0.098 & 0.110 & 0.138 \\
\hline 21 & 0.061 & 0.070 & 0.080 & 0.093 & 0.104 & 0.130 \\
\hline 22 & 0.058 & 0.067 & 0.076 & 0.088 & 0.098 & 0.123 \\
\hline 23 & 0.056 & 0.064 & 0.072 & 0.084 & 0.093 & 0.116 \\
\hline 24 & 0.053 & 0.061 & 0.069 & 0.080 & 0.089 & 0.111 \\
\hline 25 & 0.051 & 0.059 & 0.066 & 0.076 & 0.085 & 0.105 \\
\hline 26 & 0.049 & 0.056 & 0.063 & 0.073 & 0.081 & 0.100 \\
\hline 27 & 0.047 & 0.054 & 0.061 & 0.070 & 0.077 & 0.096 \\
\hline 28 & 0.046 & 0.052 & 0.058 & 0.067 & 0.074 & 0.092 \\
\hline 29 & 0.044 & 0.050 & 0.056 & 0.064 & 0.071 & 0.088 \\
\hline 30 & 0.043 & 0.048 & 0.054 & 0.062 & 0.068 & 0.084 \\
\hline 31 & 0.041 & 0.047 & 0.052 & 0.060 & 0.066 & 0.081 \\
\hline 32 & 0.040 & 0.045 & 0.050 & 0.058 & 0.063 & 0.078 \\
\hline 33 & 0.039 & 0.044 & 0.049 & 0.055 & 0.061 & 0.075 \\
\hline 34 & 0.037 & 0.042 & 0.047 & 0.054 & 0.059 & 0.072 \\
\hline 35 & 0.036 & 0.041 & 0.045 & 0.052 & 0.057 & 0.070 \\
\hline 36 & 0.035 & 0.040 & 0.044 & 0.050 & 0.055 & 0.067 \\
\hline 37 & 0.034 & 0.038 & 0.043 & 0.049 & 0.053 & 0.065 \\
\hline 38 & 0.033 & 0.037 & 0.041 & 0.047 & 0.052 & 0.063 \\
\hline 39 & 0.032 & 0.036 & 0.040 & 0.046 & 0.050 & 0.061 \\
\hline 40 & 0.032 & 0.035 & 0.039 & 0.044 & 0.048 & 0.059 \\
\hline 41 & 0.031 & 0.034 & 0.038 & 0.043 & 0.047 & 0.057 \\
\hline 42 & 0.030 & 0.034 & 0.037 & 0.042 & 0.046 & 0.055 \\
\hline 43 & 0.029 & 0.033 & 0.036 & 0.041 & 0.044 & 0.054 \\
\hline 44 & 0.029 & 0.032 & 0.035 & 0.040 & 0.043 & 0.052 \\
\hline 45 & 0.028 & 0.031 & 0.034 & 0.039 & 0.042 & 0.051 \\
\hline 46 & 0.027 & 0.030 & 0.033 & 0.038 & 0.041 & 0.049 \\
\hline 47 & 0.027 & 0.030 & 0.033 & 0.037 & 0.040 & 0.048 \\
\hline 48 & 0.026 & 0.029 & 0.032 & 0.036 & 0.039 & 0.047 \\
\hline 49 & 0.026 & 0.028 & 0.031 & 0.035 & 0.038 & 0.045 \\
\hline 50 & 0.025 & 0.028 & 0.030 & 0.034 & 0.037 & 0.044 \\
\hline
\end{tabular}


Table 2 Critical Values of K-S Test Statistic

\begin{tabular}{l|l}
\hline $\mathbf{n}$ & \multicolumn{1}{|l}{$\mathbf{D}_{\mathbf{0 . 9 5}}$} \\
\hline $\mathbf{5}$ & 0.442 \\
$\mathbf{1 0}$ & 0.324 \\
$\mathbf{2 0}$ & 0.235 \\
$\mathbf{3 0}$ & 0.193 \\
$\mathbf{4 0}$ & 0.168 \\
$\mathbf{5 0}$ & 0.151 \\
\hline
\end{tabular}

Table 3 Power Comparison: Triangle $(h=0.25)$

\begin{tabular}{l|cc}
$\mathbf{n}$ & G-TEST & K-S TEST \\
\hline $\mathbf{5}$ & 0.0205 & 0.2491 \\
$\mathbf{1 0}$ & 0.1276 & 0.5190 \\
$\mathbf{2 0}$ & 0.4102 & 0.8620 \\
$\mathbf{3 0}$ & 0.6777 & 0.9743 \\
$\mathbf{4 0}$ & 0.8623 & 0.9962 \\
$\mathbf{5 0}$ & 0.9440 & 0.9995
\end{tabular}

Table 4 Power Comparison: Triangle $(h=0.5)$

\begin{tabular}{l|cc}
$\mathbf{n}$ & G-TEST & K-S TEST \\
\hline $\mathbf{5}$ & 0.0615 & 0.4131 \\
$\mathbf{1 0}$ & 0.3034 & 0.7626 \\
$\mathbf{2 0}$ & 0.7326 & 0.9803 \\
$\mathbf{3 0}$ & 0.9443 & 0.9992 \\
$\mathbf{4 0}$ & 0.9939 & 1 \\
$\mathbf{5 0}$ & 0.9995 & 1
\end{tabular}

Table 5 Power Comparison: Triangle $(h=0.75)$

\begin{tabular}{l|cc}
$\mathbf{n}$ & G-TEST & K-S TEST \\
\hline $\mathbf{5}$ & 0.1047 & 0.4764 \\
$\mathbf{1 0}$ & 0.4174 & 0.8289 \\
$\mathbf{2 0}$ & 0.8838 & 0.9921 \\
$\mathbf{3 0}$ & 0.9930 & 0.9998 \\
$\mathbf{4 0}$ & 0.9999 & 1 \\
$\mathbf{5 0}$ & 1.0000 & 1
\end{tabular}


Table 6 Power Comparison: V-shaped Triangle $(h=0.25)$

\begin{tabular}{l|cc}
$\mathbf{n}$ & G-TEST & K-S TEST \\
\hline $\mathbf{5}$ & 0.2368 & 0.2916 \\
$\mathbf{1 0}$ & 0.5067 & 0.5396 \\
$\mathbf{2 0}$ & 0.8487 & 0.8816 \\
$\mathbf{3 0}$ & 0.9777 & 0.9813 \\
$\mathbf{4 0}$ & 0.9983 & 0.9980 \\
$\mathbf{5 0}$ & 0.9999 & 0.9998
\end{tabular}

Table 7 Power Comparison: V-shaped Triangle $(h=0.5)$

\begin{tabular}{l|cc}
$\mathbf{n}$ & G-TEST & K-S TEST \\
\hline $\mathbf{5}$ & 0.1325 & 0.1151 \\
$\mathbf{1 0}$ & 0.2313 & 0.1976 \\
$\mathbf{2 0}$ & 0.4999 & 0.4533 \\
$\mathbf{3 0}$ & 0.7533 & 0.6983 \\
$\mathbf{4 0}$ & 0.9088 & 0.8610 \\
$\mathbf{5 0}$ & 0.9679 & 0.9451
\end{tabular}

Table 8 Power Comparison: V-shaped Triangle $(h=0.75)$

\begin{tabular}{l|cc}
$\mathbf{n}$ & G-TEST & K-S TEST \\
\hline $\mathbf{5}$ & 0.0478 & 0.0549 \\
$\mathbf{1 0}$ & 0.0669 & 0.0565 \\
$\mathbf{2 0}$ & 0.1255 & 0.0765 \\
$\mathbf{3 0}$ & 0.2239 & 0.1069 \\
$\mathbf{4 0}$ & 0.3632 & 0.1470 \\
$\mathbf{5 0}$ & 0.4847 & 0.1967
\end{tabular}




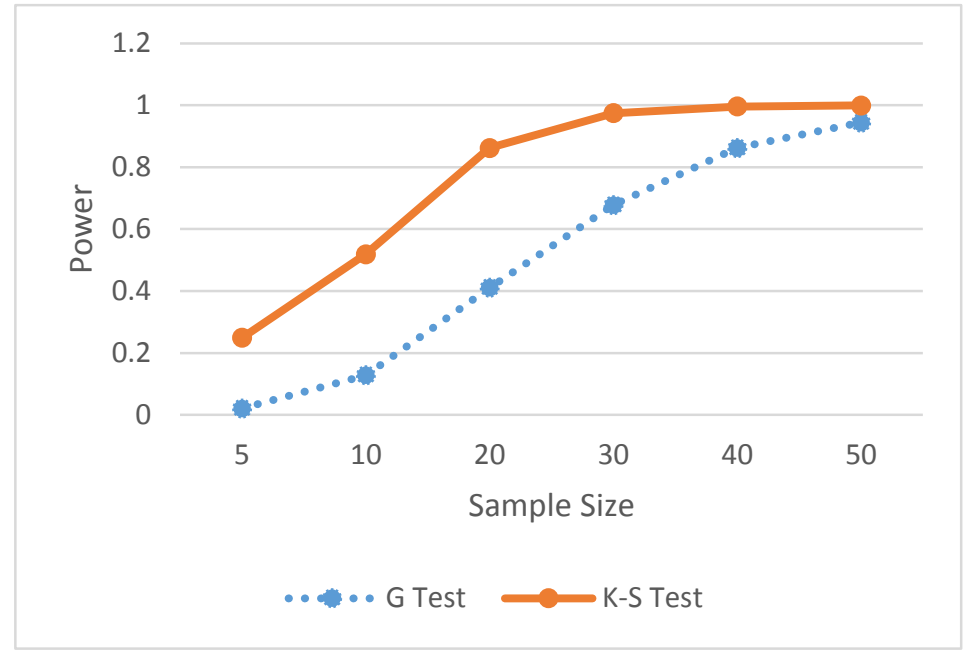

Figure 1 Alternative Distribution 1: Triangle $(h=0.25)$

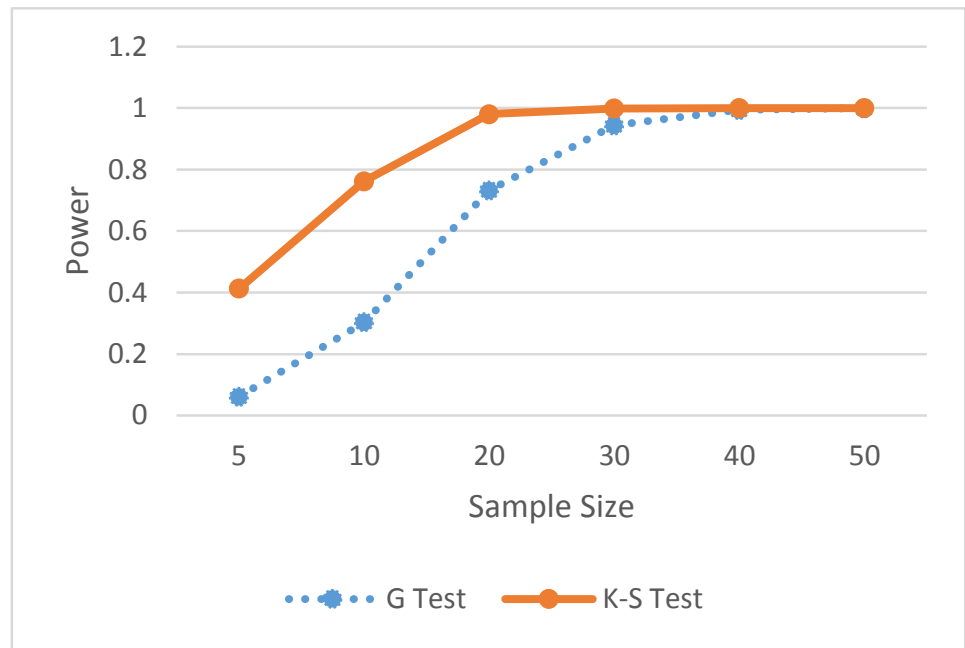

Figure 2 Alternative Distribution 2: Triangle $(\mathrm{h}=0.5)$

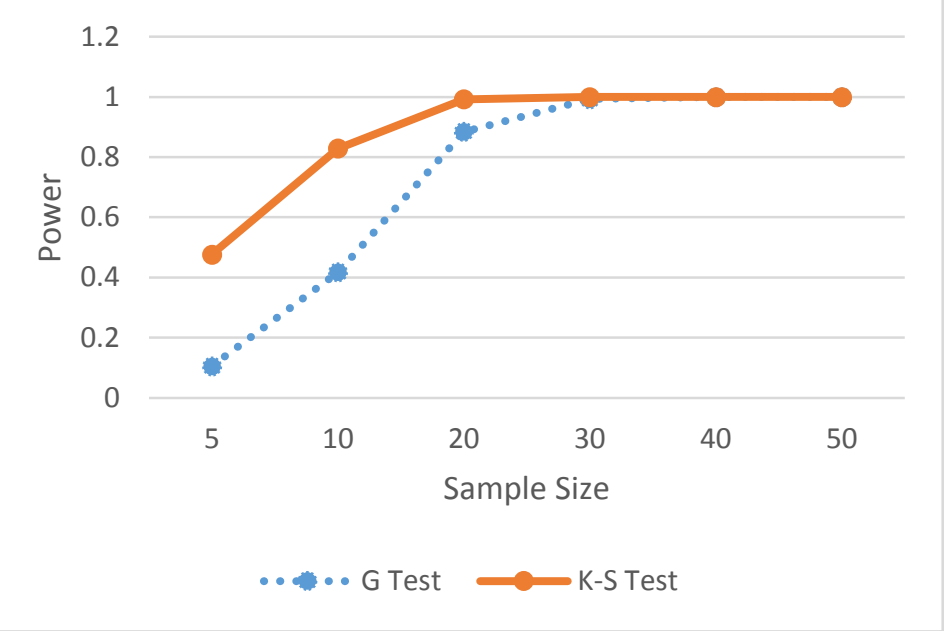

Figure 3 Alternative Distribution 3: Triangle $(\mathrm{h}=0.75)$ 


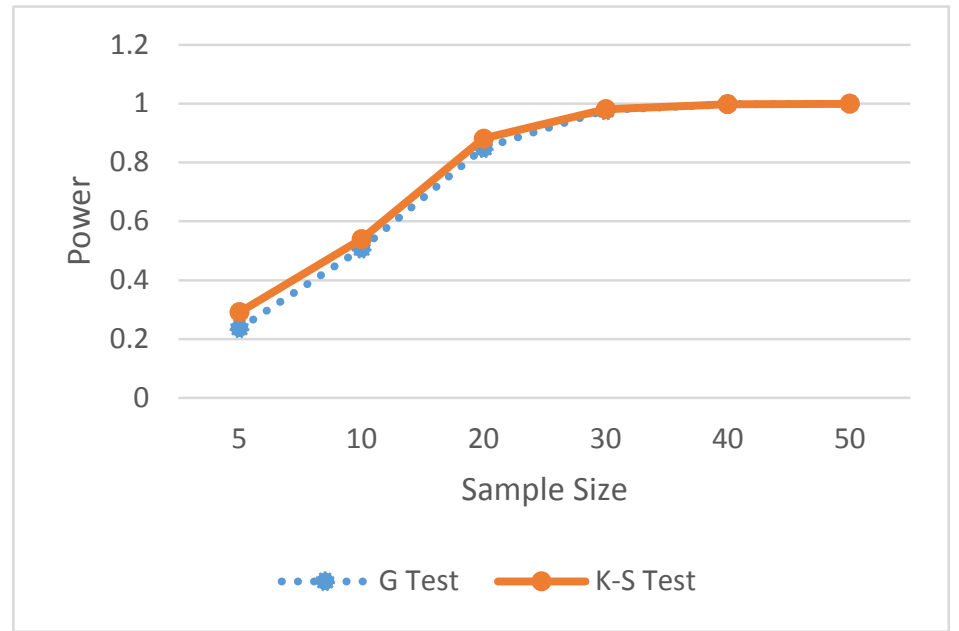

Figure 4 Alternative Distribution 4: V-shaped Triangle $(\mathrm{h}=0.25)$

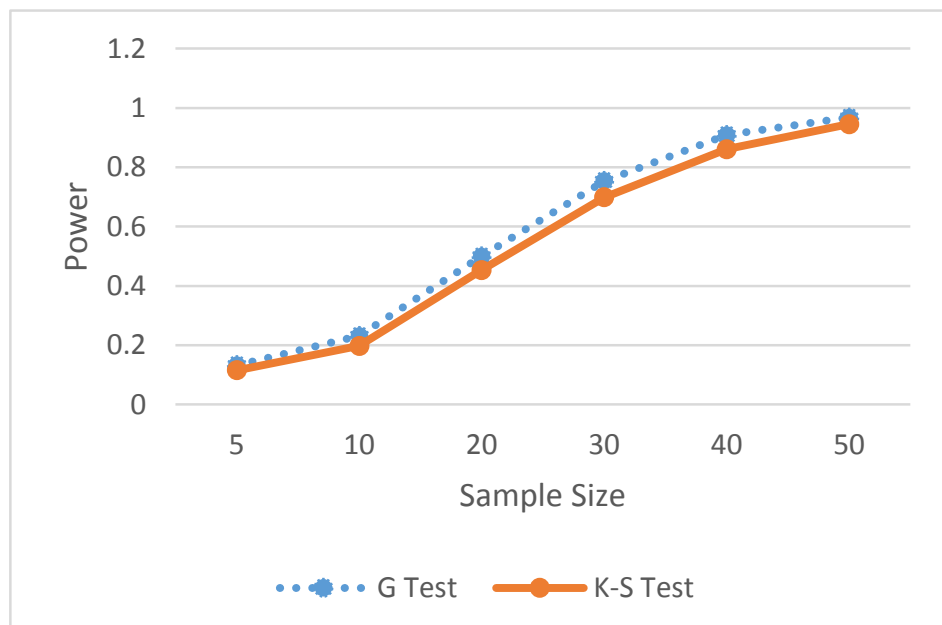

Figure 5 Alternative Distribution 5: V-shaped Triangle $(\mathrm{h}=0.5)$

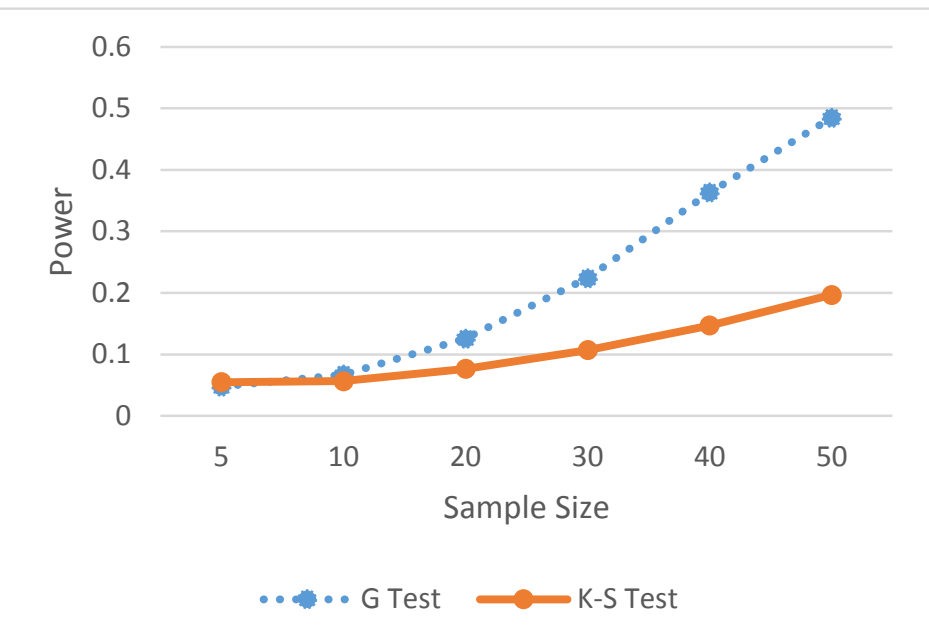

Figure 6 Alternative Distribution 6: V-shaped Triangle $(\mathrm{h}=0.75)$ 


\section{REFERENCES}

Chen, Z., Ye, C. (2009), An Alternative Test for Uniformity, International Journal of Reliability, Quality and Safety Engineering, 16: 343-356.

Diane L. Evans, John H. Drew \& Lawrence M. Leemis (2008) The Distribution of the Kolmogorov-Smirnov, Cramer-von Mises, and Anderson-Darling Test Statistics for Exponential Populations with Estimated Parameters, Communications in StatisticsSimulation and Computation, 37:7, 1396-1421.

Hubert W. Lilliefors (1969), On the Kolmogorov-Smirnov Test for the Exponential Distribution with Mean Unknown, Journal of the American Statistics Association, 64: 387-389.

Taylor B. Arnold, John W. Emerson (2011), Nonparametric Goodness-of-fit Tests for Discrete Null Distributions, The R Journal, 3/2: 34-39.

Vijay K. Rohatgi, A. K. Md. Ehsanes (2001), An Introduction to Probability and Statistics: 207-208.

W. J. Conover (1971), Practical Nonparametric Statistics: 293-298. 